\title{
Story of a Little Right Ventricular Pseudoaneurysm
}

\author{
Melek Zekiye Ulucam \\ Cardiology Department, School of Medicine, Başkent University, Ankara, Turkey \\ Email: melekulucam@gmail.com
}

Received October 17, 2012; revised November 19, 2012; accepted November 30, 2012

\begin{abstract}
Cardiac trauma caused by Swann-Ganz catheter may very rarely cause cardiac perforation, tamponade and right ventricular pseudoaneurysm. In contrast to left ventricular equivalants, pseudoaneurysms of the RV have a weak tendency to rupture. Its impact on patient outcomes should be assesed very carefully depending on its size, filling rate/capacity. It is possible not to operate the patient and follow progression of RV pseudoaneurysm by clinical and echocardiographic findings. This case is a good sample for it and describes the lifespan of a small RV pseudoaneurysm. It is not only the unique right ventricle pseudoaneurysm due to cardiac trauma caused by Swann Ganz catheter, but medically treated case without surgery and recovered completely.
\end{abstract}

Keywords: Pseudoaneurysm; Right Ventricle; Pulmonary Artery Catheterization

\section{Introduction}

Pseudoaneurysms of right ventricle (RV) are extremely rare complications of central venous catheters [1], pacemaker implantation [2], endomyocardial biopsy after cardiac transplantation $[3,4]$, pulmonary artery catheterization [5,6], cardiac trauma [7], congenital heart surgery [8], RV myocardial infarction [9]. This letter aims to describe cardiac imaging (echocardiography, cardiac catheterization) characteristics and lifespan of a small RV pseudoaneurysm which is a very rare finding after application of a Swann-Ganz catheter during cardiac surgery. Another aim is to define the therapeutic difference of left and right ventricular pseudoaneurysms.

\section{Case Report}

55-year-old male patient underwent coronary bypass surgery due to severe atherosclerotic coronary artery disease. At the end of uneventful procedure, a Swann-Ganz catheter placed to pulmonary artery via right internal jugular vein in order to monitor cardiac hemodynamics after heart surgery. As soon as chest closed, ventricular fibrillation occurred. Swann-Ganz catheter was removed, chest reopened and ventricular fibrillation treated successfully by defibrillation and cardiac massage. At same day, due to $1900 \mathrm{cc}$ pericardial drainage, a revision surgery was done, but there was not a clear source of bleeding. Echocardiographic examination after revision surgery demonstrated RV hypokinesis.

First postoperative day, blood pressure collapsed, echocardiography revealed cardiac tamponade, chest reopened and a big haematoma was removed on front of the RV. It was last decompensation of the patient, blood pressure was normal at the rest of the postoperative period.

At the 8th postoperative day, color Doppler echocardiography demonstrated a small RV pseudoaneurysm at anterolateral RV wall which has a bidirectional flow in it. (Figures 1(a)-(c)). Mass become bigger and smaller in every systole and diastole, respectively. Right ventriculography (Figures 2(a) and (b)) confirmed the diagnosis. In both studies, the neck of the pseudoaneurysm was very tight allowing very late and limited filling during every systole, so surgical treatment was not planned. Patient was followed clinically and echocardiographically. Pseudoaneurysm became progressively bigger in one month, reaching a size of $20 \times 15 \mathrm{~mm}$ (Figures 3(a) and (b)), then became progressively smaller. At the 60th day, there was no forward flow into the aneurysm. It became completely fibrotic at the 64th day (Figure 4).

\section{Discussion}

Pseudoaneurysms of the heart are very rare findings and may develop after cardiac perforation due to several reasons. Cardiac tamponade frequently precede them.

Left ventricular pseudoaneurysms are more frequent comparing with right ventricular equivalents. Conventional reasons are left ventricular perforation caused by myocardial infarction, cardiac trauma and iatrogenic causes [10].

Right ventricle perforation frequently caused by central venous catheters [1], pacemaker implantation [2], endomyocardial biopsy after cardiac transplantation [3,4], pulmonary artery catheterization [5,6,11-17], cardiac 
trauma [7], congenital heart surgery [8], RV myocardial infarction [9].

Pulmonary artery (PA) catheterization by Swann-Ganz catheter for monitoring cardiac filling pressure has been used clinically for 50 years [18,19]. Described complications are arrhythmias, knotting of the catheter [20], perforations of superior vena cava, right atrium, RV [5, 11-17] and pulmonary artery [18,21,22]. They have a incidence of $0.03 \%$ to $1 \%$ of all cases [21].

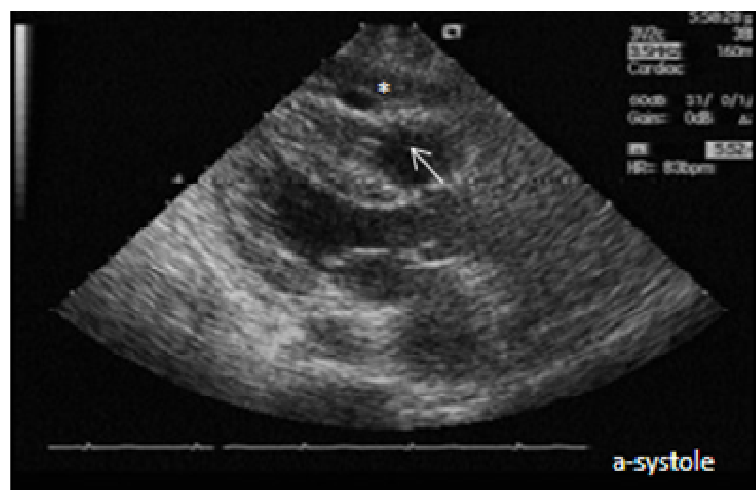

(a)

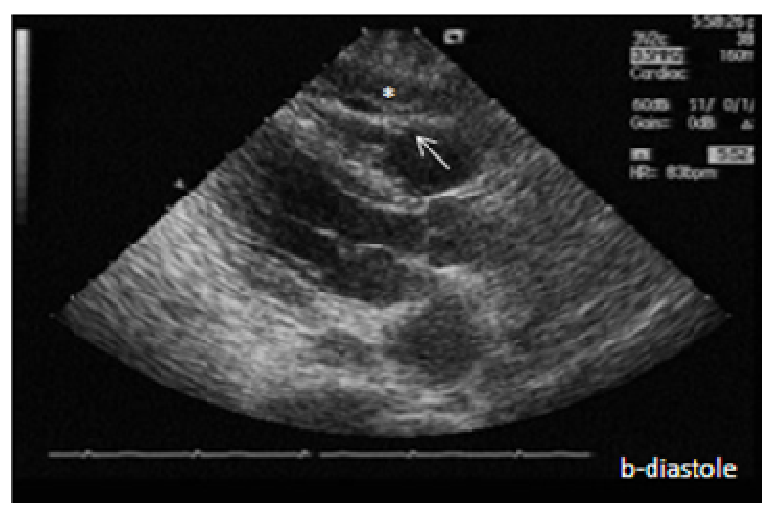

(b)

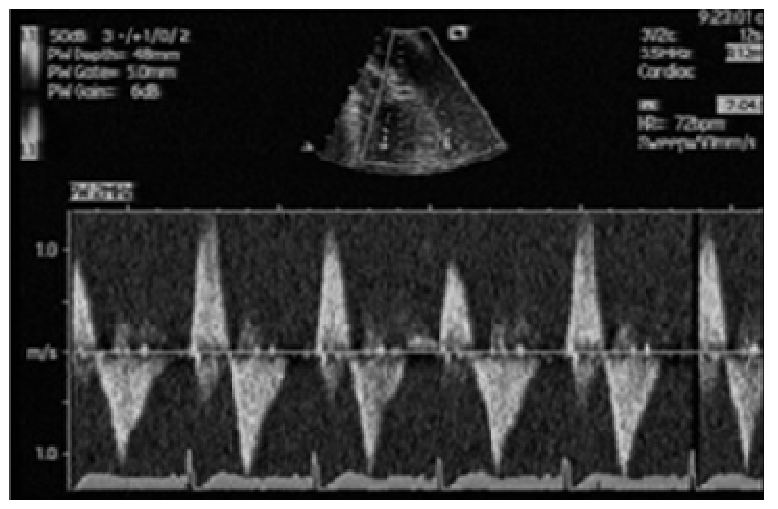

(c)

Figure 1. Right ventricular pseudoaneurysm at systole (a) and diastole (b), which has bidirectional flow (inward and outward) at the orifice (c). Star points the wall of pseudoaneurysm consisted of thick thrombus in pericardial space and arrow indicates the mouth of pseudoaneurysm.

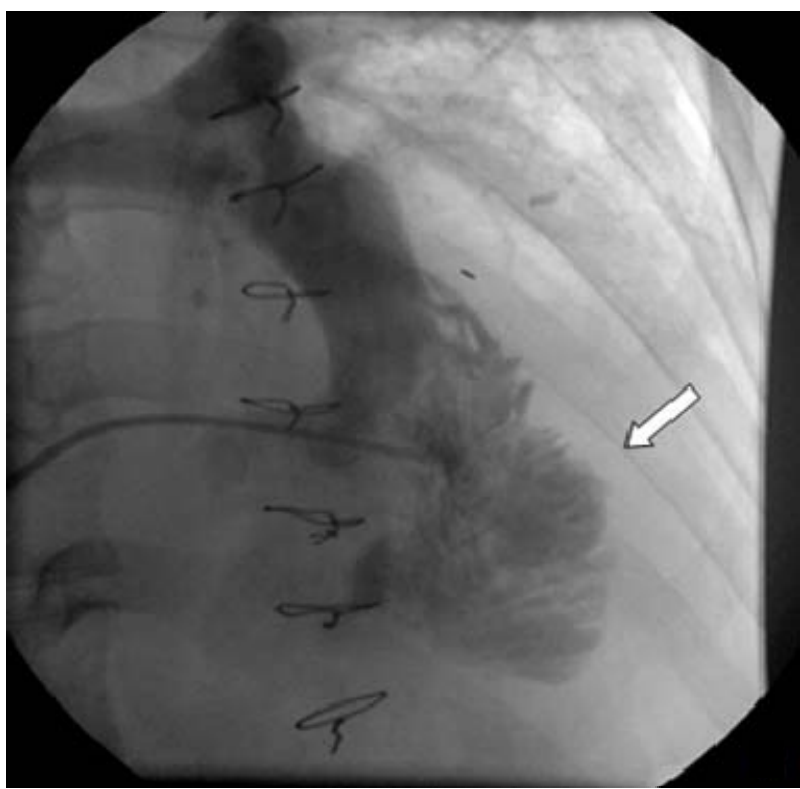

(a)

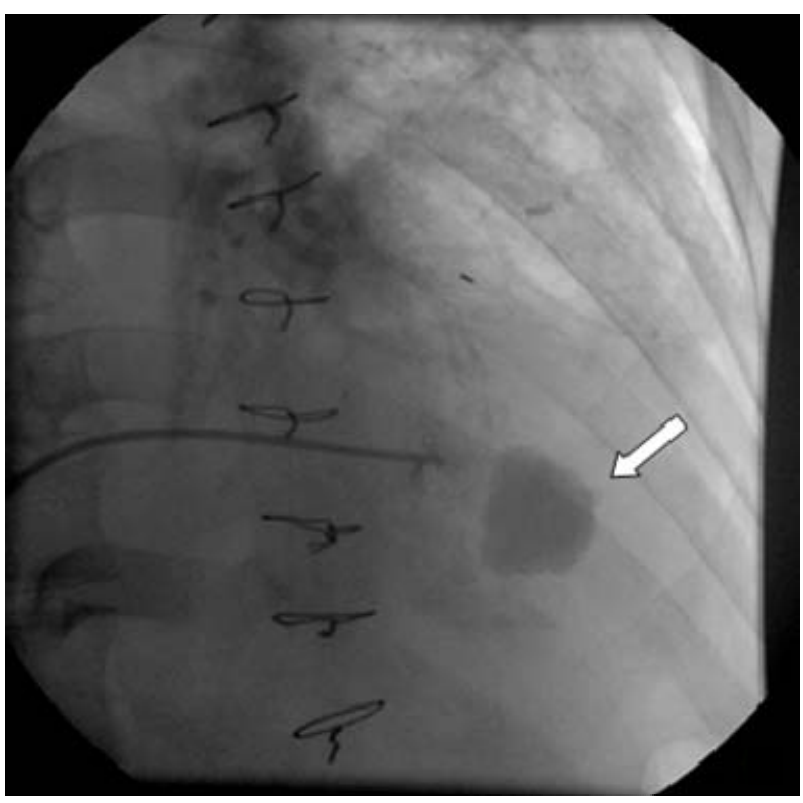

(b)

Figure 2. Right ventriculography shows pseudoaneurysm (arrows) during filling (a) and after wash-out (b) period.

Right ventricle perforation is a rare and one of the most serious complications of PA catheterization. It may not be clear during open heart surgery. The RV can form a plug around the penetrating catheter and limit cardiac tamponade [23] which can be determined immediately or weeks to months later [24]. There is no specific information about the incidence of RV perforation and cardiac tamponade due to PA catheterization. This rare complication is associated with a very high mortality. Before 1980 death rate was reported as 77\% [25]. From 1980 to 1989 this was 47\% [25]. Some reports give mortality 


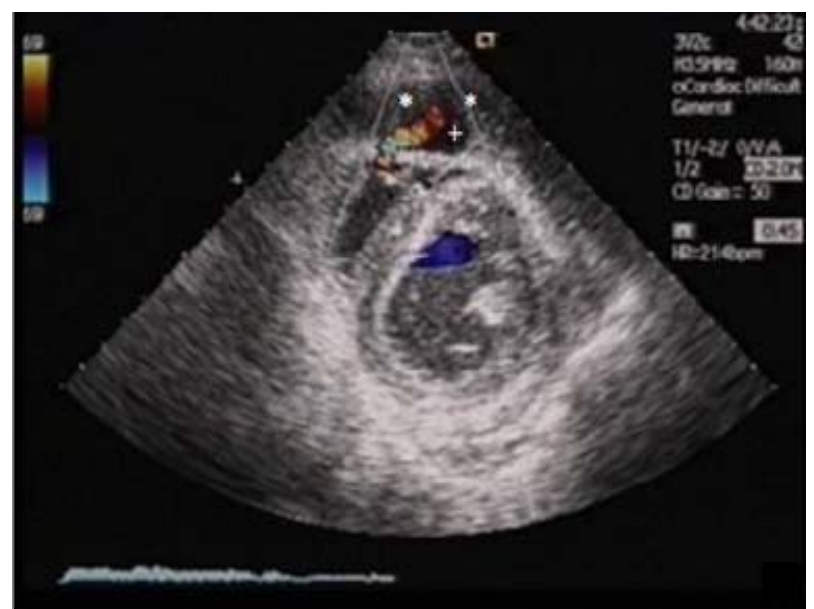

(a)

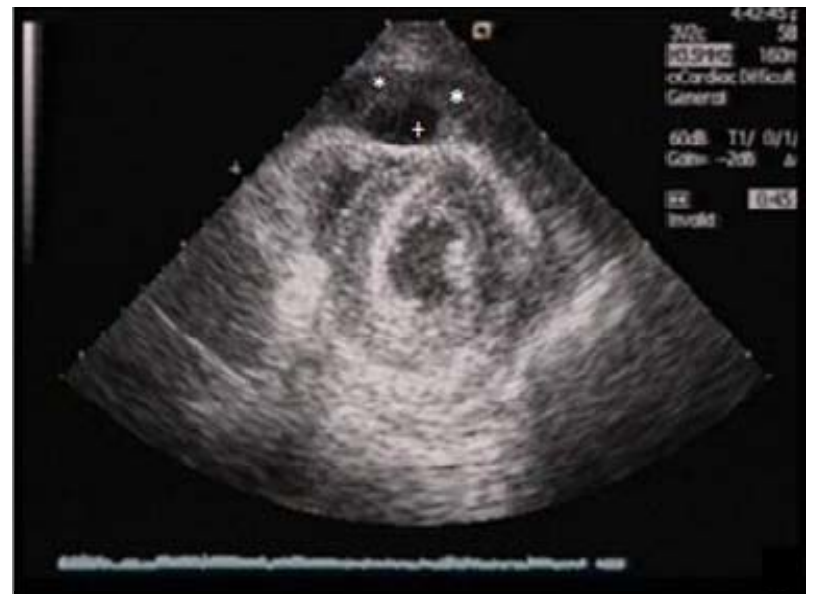

(b)

Figure 3. Parasternal short axis color doppler (a) shows flow and 2 dimensional (b) echocardiographic images reflects maximal size of the pseudoaneurysm. *The wall of pseudoaneurysm consisted of thick thrombus in pericardial space. ${ }^{+}$The lumen of pseudoaneurysm.

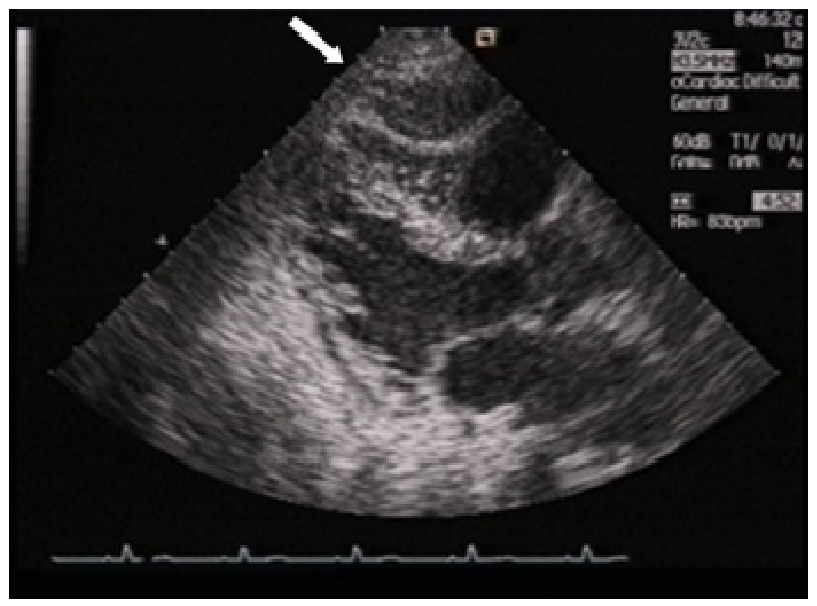

Figure 4. A large scar (arrow) replaces pseudoaneurysm at the end of healing period. A slightly pressed right ventricle is shown. rate of between $65 \%$ and $100 \%$ [26,27]. The current mortality rate is still probably great, assuming there are some unwritten cases.

Pseudoaneurysms of heart contain a thin wall which consists of parietal pericardium with thrombus and no myocardium, which makes them prone to rupture. Because of this reason, treatment strategy of left ventricular pseudoaneurysms is surgical resection as soon as possible because of their propensity to rupture [10,28]. Because of its rarity, the natural history of pseudoaneurysm of the RV is not well established. It differs from their left ventricular equivalents. The low pressure system in RV usually lets spontaneous obliteration of the neck [2]. Although surgery is an option, treatment decision should be individualized depending on the size, volume, filling rate of blood flow and complete tendency to rupture of RV pseudoaneurysm.

In our case, pseudoaneurysm of the RV could be the result of scarification of right ventricle by Swan-Ganz catheter. The location of the aneurysm was compatible with a complication of Swan-Ganz catheter deployed through right internal jugular vein. It was recognized 8 days after cardiac perforation. Due to very thin neck of aneurysm and low forward flow in it, it was preferred following patient by echocardiography while observing his clinical findings. In a two months time, pseudoaneurysm became completely fibrotic. Patient was well all over this period and he was able to be discharged. There are 8 reports for cardiac tamponade related with Swann Ganz catheter [5,11-17] but there is no case of post Swann-Ganz RV pseudoaneurysm in the literature. In addition, it is the unique case in the literature which its clinical course is followed by echocardiographically and not treated by surgical intervention. All of this these reasons, makes this case very special.

\section{Conclusion}

Cardiac trauma caused by Swann-Ganz catheter may cause life-threatening cardiac perforation, tamponade and pseudoaneurysm of RV, which is a very rare situation. Echocardiography could comprehensively diagnose the location, size and progression of the pseudoaneurysm, therefore avoiding any invasive diagnostic approach. If $\mathrm{RV}$ perforation is not diagnosed during cardiac tamponade and pseudoaneurysm develops, it is possible to follow it's progression by echocardiography and conservative therapy may be possible.

\section{REFERENCES}

[1] S. A. Booth, B. Norton and D. A. Mulvey, "Central Venous Catheterization and Fatal Cardiac Tamponade," British Journal of Anaesthesia, Vol. 87, No. 2, 2001, pp. 298-302. doi:10.1093/bja/87.2.298 
[2] X. Shen, M. J. Holmberg, J. Sype, C. Hunter, A. N. Mooss and S. M. Mohiuddin, "Real-Time Three-Dimensional Echocardiography in Diagnosis of Right Ventricular Pseudoaneurysm after Pacemaker Implantation," Echocardiography, Vol. 23, No. 3, 2006, pp. 240-243. doi:10.1111/j.1540-8175.2006.00156.x

[3] C. Rodrigues, A. de Vylder, F. Wellens, J. Bartunek and B. De Bruyne, "Right Ventricular Pseudoaneurysm as a Complication of Endomyocardial Biopsy after Heart Transplantation," Chest, Vol. 107, No. 2, 1995, pp. 566567. doi:10.1378/chest.107.2.566

[4] F. Saraiva, V. Matos, L. Gonçalves, M. Antunes and L. A. Providência, "Complications of Endomyocardial Biopsy in Heart Transplant Patients: A Retrospective Study of 2117 Consecutive Procedures," Transplant Proceedings, Vol. 43, No. 5, 2011, pp. 1908-1912. doi:10.1016/j.transproceed.2011.03.010

[5] J. Trzebicki, W. Lisik, B. Blaszczyk, M. Pacholczyk, M. Fudalej, A. Chmura, et al., "Unexpected Fatal Right Ventricular Rupture during Liver Transplantation: Case Report," Annals of Transplantation, Vol. 16, No. 1, 2011, pp. 70-74.

[6] K. Chatterjee, "The Swan-Ganz Catheters: Past, Present and Future. A Viewpoint," Circulation, Vol. 119, No. 1, 2009, pp. 147-152. doi:10.1161/CIRCULATIONAHA.108.811141

[7] J. Moen, W. Hansen, K. Chandrasekaran and J. B. Seward, "Traumatic Aneurysm and Pseudoaneurysm of the Right Ventricle: A Diagnosis by Echocardiography," Journal of the American Society of Echocardiography, Vol. 15, No. 9, 2002, pp. 1025-1026. doi:10.1067/mje.2002.122079

[8] M. Karimi, A. Farouk, J. Stork and H. A. Hennein, "Right Ventricular Aneurysm Following Modified NorwoodSano Operation for Hypoplastic Left Heart Syndrome," Interactive CardioVasc Thoracic Surgery, Vol. 7, No. 4, 2008, pp. 664-666. doi:10.1510/icvts.2007.171777

[9] C. Arslan, B. Kayhan, T. Turan and L. Kaplan, "Right Ventricular Pseudoaneurysm after Myocardial Infarction," Turkish Journal of Thoracic and Cardiovascular Surgery, Vol. 12, 2004, pp. 128-129.

[10] E. Eren, N. Bozbuga, M. E. Toker, C. Keles, M. B. Rabus, O. Yildirim, et al., "Surgical Treatment of Post-Infarction Left Ventricular Pseudoaneurysm: A Two-Decade Experience," Texas Heart Institute Journal, Vol. 34, No. 1, 2007, pp. 47-51.

[11] D. Karakaya, S. Baris and A. Tur, "Pulmonary Artery Catheter-Induced Right Ventricular Perforation during Coronary Artery Bypass Surgery," British Journal of Anaesthesia, Vol. 82, No. 6, 1999, p. 953. doi:10.1093/bja/82.6.953

[12] M. A. Lyew, D. R. Bacon and M. S. Nesarajah, "Right Ventricular Perforation by a Pulmonary Artery Catheter during Coronary Artery Bypass Surgery," Anesthesia \& Analgesia, Vol. 82, No. 5, 1996, pp. 1089-1090.

[13] M. Auxiliadora-Martins, E. Apinagés Dos Santos, D. Adans Wenzinger, G. C. Alkmim-Teixeira, G. C. de M Neto, A. K. Sankarankutty, et al., "Perforation of the Right Ventricle induced by Pulmonary Artery Catheter at Induction of Anesthesia for the Surgery for Liver Trans- plantation: A Case Report and Reviewed of Literature," Case Reports in Medicine, Vol. 2009, 2009, p. 650982. doi: $10.1155 / 2009 / 650982$

[14] K. C. Chuang, A. K. Lan, H. N. Luk, C. S. Wang, C. J. Huang, K. W. Cheng, et al., "Perforation of the Right Ventricle by a Pulmonary Artery Catheter that Continues to Measure Cardiac Output and Mixed Venous Saturation," Journal of Clinical Anesthesia, Vol. 17, No. 2, 2005, pp. 124-127. doi:10.1016/j.jclinane.2004.05.008

[15] J. A. Cohen, R. H. Blackshear, N. Gravenstein and J. Woeste, "Increased Pulmonary Artery Perforating Potential of Pulmonary Artery Catheters during Hypothermia," Journal of Cardiothoracic and Vascular Anesthesia, Vol. 5, No. 3, 1991, pp. 234-236. doi:10.1016/1053-0770(91)90280-7

[16] C. M. Domaingue and A. L. White, "Right ventricular Perforation in a Patient with a Pulmonary Artery Catheter," Journal of Cardiothoracic Anesthesia, Vol. 2, No. 2, 1988, pp. 223-224. doi:10.1016/0888-6296(88)90276-1

[17] S. P. Maschke and H. J. Rogove, "Cardiac Tamponade Associated with a Multilumen Central Venous Catheter," Critical Care Medicine, Vol. 12, No. 7, 1984, pp. 611613. doi:10.1097/00003246-198407000-00017

[18] H. J. Swan, W. Ganz, J. Forrester, H. Marcus, G. Diamond and D. Chonette, "Catheterisation of Heart in Man with Use of a Flow-Directed Balloon Tipped Catheter," The New England Journal of Medicine, Vol. 283, No. 9, 1970, pp. 447-451. doi:10.1056/NEJM197008272830902

[19] K. B. Shah, T. L. Rao, S. Laughlin and A. A. El-Etr, "A Review of Pulmonary Artery Catheterization in $6245 \mathrm{~Pa}-$ tients," Anesthesiology, Vol. 61, No. 3, 1984, pp. 271-275. doi:10.1097/00000542-198409000-00007

[20] N. B. Bagul, N. J. Menon, R. Pathak, A. Platts and G. Hamilton, "Knot in the Cava-An Unusual Complication of Swan-Ganz Catheter," European Journal of Vascular and Endovascular Surgery, Vol. 29, No. 6, 2005, pp. 651-653. doi:10.1016/j.ejvs.2005.02.017

[21] T. B. Bossert, J. F. Gummert, H. B. Bittner, M. Barten, T. Walther, V. Falk, et al., "Swan Ganz Catheter Induced Severe Complicaton in Cardiac Surgery: Right Ventricular Perforation, Knotting, and Rupture of a Pulmonary Artery," Journal of Cardiac Surgery, Vol. 21, No. 3, 2006, pp. 292-295. doi:10.1111/j.1540-8191.2006.00235.x

[22] P. G. Barash, D. Nardi, G. Hammond, G. Walker-Smith, D. Capuano, H. Laks, et al., "Catheter-Induced Pulmonary Artery Perforation, Mechanisms, Management and Modifications," The Journal of Thoracic and Cardiovascular Surgery, Vol. 82, No. 1, 1981, pp. 5-12.

[23] P. F. Cohn and E. Braunwald, "Traumatic Heart Disease," In: E. Braunwald, Ed., Heart Disease: A Textbook of Cardio-vascular Medicine," W.B. Saunders, Philadelphia, 1992, pp. 1517-1527.

[24] Y. G. Cherng, Y. J. Cheng, T. G. Chen, C. M. Wang and C. C. Liu, "Cardiac Tamponade in an Infant-A Rare Complication of Central Venous Catheterization," Anaesthesia, Vol. 49, No. 12, 1994, pp. 1052-1054. doi:10.1111/j.1365-2044.1994.tb04354.x 
[25] G. Nasim, G. Cooper and A. K. Ah-See, "Cardiac Tamponade Due to Central Venous Catheterization," Journal of the Royal College of Surgeons of Edinburgh, Vol. 37, No. 5, 1992, pp. 337-339.

[26] P. E. Collier, J. J. Ryan and D. L. Diamond, "Cardiac Tamponade from Central Venous Catheters. Report of a Case and Review of the English Literature," Angiology, Vol. 35, No. 9, 1998, pp. 595-600. doi:10.1177/000331978403500909
[27] J. S. Rutherford, A. F. Merry and C. J. Occleshaw, "Depth of Central Venous Catheterization: An Audit of Practice in a Cardiac Surgical Unit," Anaesthesia and Intensive Care, Vol. 22, 1994, pp. 267-271.

[28] P. Harrity, A. Patel, J. Bianco and R. Subramanian, "Improved Diagnosis and Characterization of Postinfarction Left Ventricular Pseudoaneurysm by Cardiac Magnetic Resonance Imaging," Clinical Cardiology, Vol. 14, No. 7, 1991, pp. 603-606. doi:10.1002/clc.4960140713 